\title{
A tale of 10 European centres - 2010 APOSSM travelling fellowship review in ACL surgery
}

Yee Han Dave Lee ${ }^{1 *}$, Ryosuke Kuroda ${ }^{2}$, Jinzhong Zhao ${ }^{3}$ and Kai Ming Chan ${ }^{4}$

\begin{abstract}
The purpose of ESSKA- APOSSM Travelling fellowship is to better understand the epidemiology, management and surgical techniques for sports across continents. There has been a progressive evolution in ACL reconstruction and there is variation in technique in $\mathrm{ACL}$ reconstruction amongst the most experienced surgeons in different continents. During this one month fellowship, we saw various $A C L$ reconstruction techniques using different graft sources, with a variety of graft fixation methods, with the common aim of recreating an anatomical ACL reconstruction.
\end{abstract}

\section{Introduction}

The Anterior Cruciate Ligament(ACL) is well studied ligament and there has been a progressive evolution in ACL reconstruction technique that is documented in the literature. The industry has aided this evolution with the improvements in implant design and biomaterial sciences. There is variation in technique in ACL reconstruction amongst the most experienced surgeons in different continents.

The purpose of ESSKA- APOSSM Travelling fellowship was to gain a better understanding into sports surgery- its epidemiology, management and surgical techniques across continents. As participants of this month long travelling fellowship, we had the opportunity to visit ten top European Sports centres in seven countries.

\section{Methods}

During this travelling fellowship, we had seen numerous ACL reconstructions - each different in surgical technique. Each of the centre that we visited were recoginsed as a premier European sports knee reconstruction and the surgeons there performed an average of 150 to $200 \mathrm{ACL}$ reconstructions annually. It represents a good dichotomy of how ACL reconstruction is performed in the European continent and we felt it was beneficial to review this as it crystalises where we are with ACL reconstruction in 2011.

\footnotetext{
* Correspondence: davelyh@singnet.com.sg

'Department of Orthopedic Surgery, Changi General Hospital, 2 Simei St 3, Singapore 529889, Singapore

Full list of author information is available at the end of the article
}

\section{Results}

1. All the grafts in the ACL reconstructions we saw were autograft tissue. We had 6 cases where Hamstring autograft tendon and 4 cases where bone patella tendon bone (BTB) graft was used. Table 1 summarises the breakdown of graft types during this fellowship.

2. The majority of centres perform a single femur and tibial tunnel ACL reconstruction, with the aim of recreating the ACL anatomical footprint. There was one case of double bundle ACL reconstruction that was performed in one of the centres.

3. We saw that no notchplasties were performed in ACL footprint preparation, except in BTB ACL reconstruction and chronic ACL reconstructions.

4. All the femoral tunnels were drilled independently through the anteromedial portal except for two cases; a BTB ACL reconstruction with transtibial femoral tunnel drilling and an outside-in femoral tunnel drilling for revision ACL reconstruction.

5. The majority of hamstring graft fixations on the femoral side was accomplished with cortical suspensory fixation. One hamstring graft ACL reconstruction was performed as an all-inside technique with bioabsorbable interference screw fixation on the femur. For hamstring grafts, the tibial fixation were all achieved with bioabsorbable interference screws. In two centres, we note the practice of backup the tibia fixation with staples in addition to the tibia screws. 
Table 1 Breakdown of graft sources

\begin{tabular}{lll}
\hline & $\begin{array}{l}\text { Primary ACL } \\
\text { Surgery (Cases) }\end{array}$ & $\begin{array}{l}\text { Revision ACL } \\
\text { Surgery (Cases) }\end{array}$ \\
\hline Hamstring autograft & 5 & 1 \\
\hline $\begin{array}{l}\text { Bone Patella Tendon Bone } \\
\text { autograft }\end{array}$ & 2 & 2 \\
\hline
\end{tabular}

6. For BTB ACL reconstructions, fixation on the femur and tibia were achieved with metal or bioabsorbable interference screws, except for one centre; where they used a direct cortical button technique. All the BTB ACL reconstructions were fixed on the tibia side with interference screws, either metal or bioabsorbable. Table 2 sumarises the femoral and tibia fixation methods used.

7. The majority of ACL reconstruction were performed surgery at approximately one month after the injury. However, we are aware that some centres in the alpine region treating ski injuries perform acute ACL reconstruction within a week of injuries.

8. We saw was the importance all European centres placed on preserving the meniscus in ACL reconstruction surgery. Meniscus that were reparable were repaired with all-inside meniscal repair methods, inside -out and outside-in methods.

9. There were 2 combined cases of ACL reconstruction and high tibial osteotomy for chronic ACL injuries with varus alignment. Both procedures started with the osteotomy and was followed by drilling of the tunnels for ACL reconstruction. We did not note any compromise to the positions of the tunnels during the ACL reconstruction as a results of the combined surgery.

10.There were 3 Revision ACL Reconstructions performed for traumatic reinjuries. All the cases were single stage autograft ACL revisions; 2 cases used ipsilateral BTB autograft and the other used contralateral Hamstring autograft as all 3 patients had previous hamstring ACL reconstruction.

\section{Discussion}

\section{Graft Choice}

In European centres, the use of allograft tissue is not prevalent. Allograft tissue is not readily available in many countries and only permitted for use when all

Table 2 Types of graft fixation methods in the femur

\begin{tabular}{lllll}
\hline & Endobutton & $\begin{array}{l}\text { Bioabsorbable } \\
\text { Screws }\end{array}$ & $\begin{array}{l}\text { Metal } \\
\text { Screws }\end{array}$ & Remarks \\
\hline Hamstring & 4 & 1 & 0 & $\begin{array}{l}1 \text { Evolgate } \\
\text { Swing bridge }\end{array}$ \\
\hline BTB & 1 (direct) & 1 & 2 & \\
\hline
\end{tabular}

other autograft sources are exhausted. From our literature review summarised in Table 3, two graft choice trends in ACL surgery are apparent. Over the last 5 to ten years, we see the increased use of allograft tissue in ACL surgery in American centres. In addition, the American surgeons are generally biased towards the use of Bone Patellar Tendon Bone autografts as compared to Hamstring autograft, compared to European surgeons [1-6].

In addition, we note many European surgeons are comfortable with the use of both Bone patella tendon bone and Hamstring autografts for ACL reconstruction Over the last few years, European and Asia-Pacific centres have seen increased rates of Hamstring grafts as the primary graft source. This trend was seen during this travelling fellowship.

There are basic science and clinical studies that highlight the concerns of allograft tissue use in ACL reconstruction. Scheffler et al. found in a sheep model that there was delayed allograft incorporation at 6 and 12 weeks when compared to autograft. This differences was less distinct at 52 weeks. The authors felt that full weightbearing should be delayed in allograft ACL reconstruction [8]. Singhal et al. reports of high failure rates of $38 \%$ after ACL tibialis anterior allograft surgery in their clinical study and cautioned the use of interference screw fixation and an accelerated rehabilitation protocol with allograft ACL reconstructions [9]. However, there are many other authors with 5 and 10 year clinical follow-ups of allograft ACL reconstruction that have comparable clinical outcomes when compared to autograft reconstructions [10-12].

Biomechanical studies have shown that the various allograft and autograft sources used today surpass the native ACL, when compared for ultimate load to failure and stiffness [13-18]. Table 4 summaries this information. The BTB graft has the advantage of direct bone-tobone contact for rapid incorporation. The BTB graft achieves direct attachment with Sharpey-like fibres found at the interface with the bone tunnel, resembling normal ACL at 12 weeks in a canine model [19]. Grana et al. found indirect healing between host bone and soft tissue when soft tissue hamstring grafts are used [20]. Rodeo et al. reported that Sharpeys fibres were identified by 12 weeks for soft tissue grafts, but they only reached maturity at 26 weeks [19]. Rehabilitation protocols have been designed to take this slower graft incorporation with soft tissue grafts into account.

Various authors have found that hamstring autografts have less anterior knee pain, extension deficits and progression to osteoarthritis, compared to BTB ACL reconstructions [21-23]. Wagner at al in their prospective matched analysis of hamstring autograft versus BTB ACL reconstruction found hamstring grafts superior in 
Table 3 Graft Choices among surgeons worldwide from 2000-2010

\begin{tabular}{|c|c|c|c|c|}
\hline Literature & Autograft Hamstring & Autograft BTB & Allograft & Remarks \\
\hline Mirza F et al. [7] & $32 \%$ & $59 \%$ & & Remaining used other $\mathrm{ACL}$ reconstruction techniques \\
\hline \multicolumn{5}{|l|}{2000 Survey of Canadian Surgeons } \\
\hline Feller et al. [4] & $50 \%$ & $50 \%$ & & \\
\hline \multicolumn{5}{|l|}{2001 Survey Australian Surgeons } \\
\hline Kapoor et al. [5] & $37 \%$ & $63 \%$ & & \\
\hline \multicolumn{5}{|l|}{2002 Survey of 192 UK Knee surgeons } \\
\hline Campbelll J et al. [2] & $25 \%$ & $70 \%$ & $5 \%$ & Mainly US Surgeons \\
\hline \multicolumn{5}{|l|}{2004 ACL Study Group } \\
\hline Dequin et al. [3] & $32 \%$ & $46 \%$ & $22 \%$ & \\
\hline \multicolumn{5}{|l|}{2006 AOSSM Survey } \\
\hline Barker JU [1] & $11.1 \%$ & $45.7 \%$ & $43.1 \%$ & \\
\hline \multicolumn{5}{|l|}{ 2002-2006 HSS data } \\
\hline Magnussen et al. [6] & $44 \%$ & $42 \%$ & $13 \%$ & Remaining $0.6 \%$ used other autograft sources \\
\hline \multicolumn{5}{|l|}{2010 MOON Cohort US Surgeons } \\
\hline Magnussen et al. [6] & $60 \%$ & $37 \%$ & $0.1 \%$ & Remaining $3 \%$ used other autograft sources \\
\hline 2010 NKLR Norwegian Surgeons & & & & \\
\hline
\end{tabular}

knee function and function, based on outcome scorings and instrumented laxity measurements [24]. However, Biau et al. in their metaanalysis of pooled data from 6 Randomised Controlled Trials (RCTs); concluded that there was less knee instability after BTB autograft ACL reconstruction than with hamstring autograft [25]. Other authors have found that there no difference between patients reconstructed with hamstring or BTB autografts at 5-10 year follow-up, based on knee function scores, instrumented laxity testing and repeat radiographs to look for progression of osteoarthritis [26-28]. Samuelsson $\mathrm{K}$ et al. in their systematic review of ACL surgery with special reference to graft type and surgical technique found that in terms of laxity and clinical outcomes, there was no differences between the bone patellar tendon bone and hamstring autografts [29].

\section{Double bundle ACL Techniques}

Muneta et al. first described the technique of double bundle ACL reconstruction in 1999 [30]. There has been a trend towards double bundle ACL reconstruction among sports surgeons [31,32]. In cadaveric studies, it is shown that anatomic double bundle ACL reconstruction better restores the normal patellofemoral contact pressures [33], tibiofemoral joint pressures at low flexion angles [34], rotational stability [35], the anteriorposterior and medial-lateral laxities than single bundle reconstruction [36]. With the use of a robot sensor test system in cadaver knees, it has been also shown double bundle ACL reconstruction better restores the intact knee kinematics [37]. The differential anteromedial and posterolateral bundle tensioning in double bundle ACL reconstructions more closely replicate native ACL strain patterns [38].

$\mathrm{Fu} \mathrm{FH}$ et al. reported good 2-year outcomes for 100 consecutive double bundle ACL reconstructions, based on knee function scores and instrumented laxity testing [39]. Other studies that compare double bundle ACL reconstructions against single bundle ACL reconstructions have not shown improved knee outcomes [40-42]. Similarly, Song EK et al. found that double-bundle ACL reconstructions had better intraoperative stability than single bundle ACL reconstructions; but both were similar in 2-year post-operative clinical outcomes and stabilities [43]. A Metaanalysis by Meredick comparing single-bundle versus double-bundle ACL reconstruction RCTs concluded no

Table 4 Biomechanical studies of the various graft choices

\begin{tabular}{llll}
\hline & Ultimate Load $\mathbf{( N )}$ & Stiffness(N/mm) & Remarks \\
\hline Native ACL & 2160 & 242 & Woo et al. [13] \\
\hline Doubled Hamstring Autograft & 4140 & 807 & Hamner et al. [14] \\
\hline BTB autograft & 2977 & 450 & Cooper et al. [15] \\
\hline BTB allograft fresh frozen & 2252 & 633 & Fiedeler et al. [16] \\
\hline Soft tissue allograft fresh frozen & 4122 & 625 & Haut-Donahue et al. [17] \\
\cline { 3 - 4 } & & & Pearsall aw et al. [18] \\
\hline
\end{tabular}


significant differences in instrumented laxity or pivot- shift testing [44].

With these non-conclusive data, some authors have suggested that the current knee outcome measures are not sensitive or precise enough [45]. The pivot shift test performed is different in the hands of different individuals. There has been a call for the use of more sensitive instruments advanced imaging modalities to detect early cartilage changes to compare outcomes.

\section{Anatomic $\mathrm{ACL}$}

Anatomic ACL is defined as the functional restoration of the ACL to its native dimensions, collagen orientation and insertions sites $[46,47]$. This means using landmarks on the femur and tibia to re-establish the ACL footprint as accurately as possible. All the European centres that we visited practise the concept of an anatomical ACL reconstruction (Figure 1).

The research in the 1990s described the isometric position for the femoral attachment of the ACL graft and sports surgeons strived to achieve an isometric ACL reconstruction, often combined with a notchplasty $[48,49]$. Cadaveric and biomechanical studies have shown that the native ACL is non-isometric. It has been shown that a femoral tunnel position within the anatomical footprint of the ACL results in more normal knee kinematics than a tunnel position located for best graft isometry [50]. An anatomical femoral tunnel position is important to restore the normal kinematics of the knee as demonstrated by Abebe et al [51]. It is now believed that recreating the insertional footprint anatomically as well as the tension of the two bundle concept of the anterior cruciate ligament re-establishes the function of the anterior cruciate ligament.

Cadaveric studies have been performed to define the anatomical footprint of the ACL [52-55]. For the femoral footprint of the ACL, the lateral intercondylar ridge also known as Residents ridge is located on the medial wall of the lateral femoral condyle. Shino K et al. has demonstrated this landmark - the Resident's ridge is readily identifiable on arthroscopy [56]. It runs from anterior to posterior with the knee in 90 degrees and seen from the medial portal. The lateral bifurcate ridge runs perpendicular to the lateral intercondylar ridge and is located between the AM and PL bundles. Many surgeons now identify the anatomy of the native femoral insertion during reconstruction and often no longer depend on guides as a reference.

One technical pearl that we have learnt from our visit to one of the centres was a reproducible method to locate the ACL femoral insertion site. They suggest that centre of the ACL insertion lies at a point $50 \%$ along a line drawn from the proximal articular cartilage border and the distal articular cartilage parallel to the tibial surface, with the knee at 90 degrees [57].

The tibial insertion of the ACL is taken as from the remnant of the ACL stump or referenced against the anterior insertion of the lateral meniscus. This is aligned with the anteromedial aspect of the ACL insertion. The posterolateral bundle of the ACL is aligned to the posterior attachment of the lateral meniscus [58]. Some surgeons reference the ACL insertion to a distance of approximately $7 \mathrm{~mm}$ anterior to the anterior edge of the PCL $[59,60]$. The criticism is that this may place the ACL tibial insertion too posterior. The transverse ligament

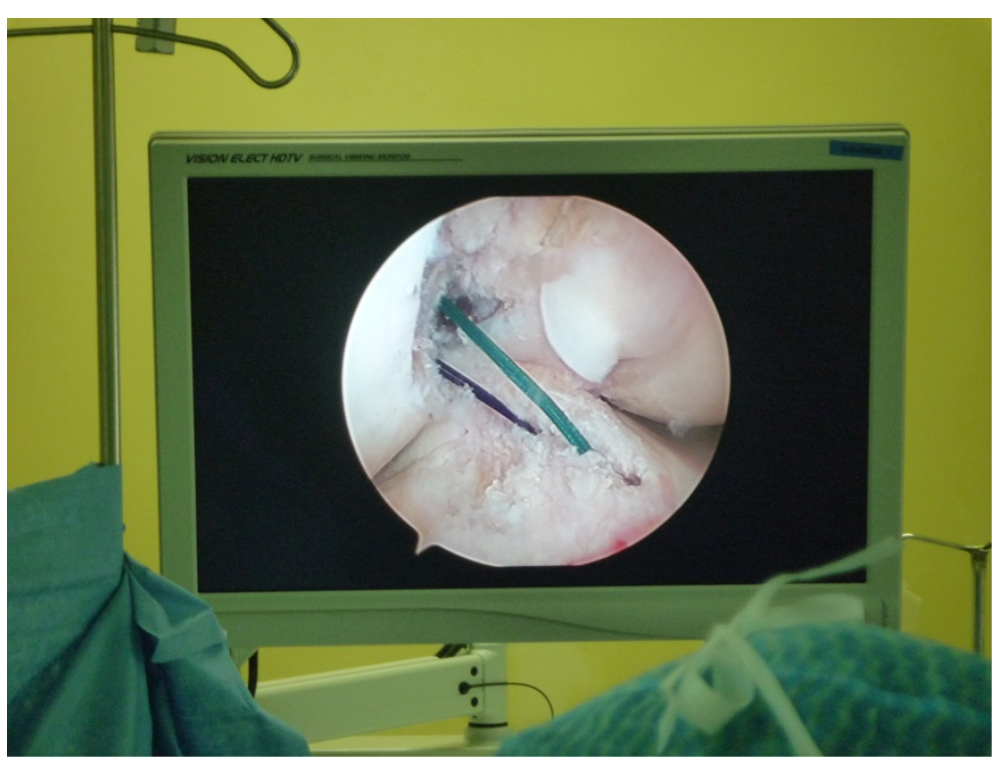

Figure 1 Anatomical ACL construction viewing from the anterolateral portal prior to grafts passed. 
coincides with the anterior edge of ACL tibial foot print, which considered as a new landmark for tibial tunnel positioning during anatomic ACL reconstruction [61].

In the ACL reconstruction, augumentation without resection of the ACL remnant using an autograft tendon is important new technique. The ACL remnant has the proprioceptive, biomechanical functions, and vascularity. More rapid vascularization from the ACL remnant to the grafted tendon and improved recovery of proprioceptive function with this technique can be expected. The utilities of this procedure are improved joint stability, position sense, and superior reported knee outcome scores [62,63].

\section{Notchplasty}

Notchplasty had been previously advocated to reduce the amount of notch impingement and ACL graft injury. Some authors believe that this makes the reconstruction easier by visualising the posterolateral margin of the intercondylar space more clearly [64]. Van Eck et al. in their evidence based review of recent articles published on the anatomic ACL reconstruction, reported that only $12 \%$ of studies performed a notchplasty [65]. In the age of anatomic ACL reconstruction, performing a notchplasty seems to be less common and this was what we saw during this travelling fellowship.

There are three concerns in the literature with performing a notchplasty. LaPrade et al. found that in a canine model study that aggressive notchplasty caused cartilage changes seen on histology at six months, consistent with early arthritis [66]. Markolf et al. in their cadaveric study found that a notchplasty created unfavourable graft forces, graft elongation and failure. They recommended removing as little bone as possible during the notchplasty [67]. The other concern is the removal of osseous landmarks of the ACL femoral insertion and compromise anatomic placement [65].

\section{Femoral drilling}

The literature now shows that transtibial femoral tunnel drilling has many drawbacks. Despite an ideal tibial tunnel position, Bedi et al. found in a cadaveric study that the femoral tunnel drilled transtibial was anterior and superior to the femoral footprint [68]. They concluded that independent anteromedial portal drilling allows accurate positioning in the centre of the native footprint. Alentorn-Geli et al. reported that anteromedial portal drilling for BTB ACL reconstructions significantly improved the anterior-posterior and rotational knee stability, functional outcome scores compared to the transtibial technique [69].

An audience poll at 2010 Fall AANA revealed that more than $50 \%$ of surgeons in the audience drilled their femoral tunnels through a transtibial technique. During this travelling fellowship, the majority of the femoral tunnels were drilled independently from the anteromedial portal (Figure 2). The key concerns with anteromedial portal drilling are: short femoral tunnel length, injury to the cartilage, injury to posterolateral knee structures and posterior wall blow-out [70-72].

One key technical pearl that we have learnt is the importance of hyperflexion with anteromedial portal drilling as alluded to by Nakamura et al [73]. All the surgeons that we visited drilled the femoral tunnel through the anteromedial portal did so with flexion beyond 120 degrees. It has been shown that anteromedial drilling has to be performed with hyperflexion of the

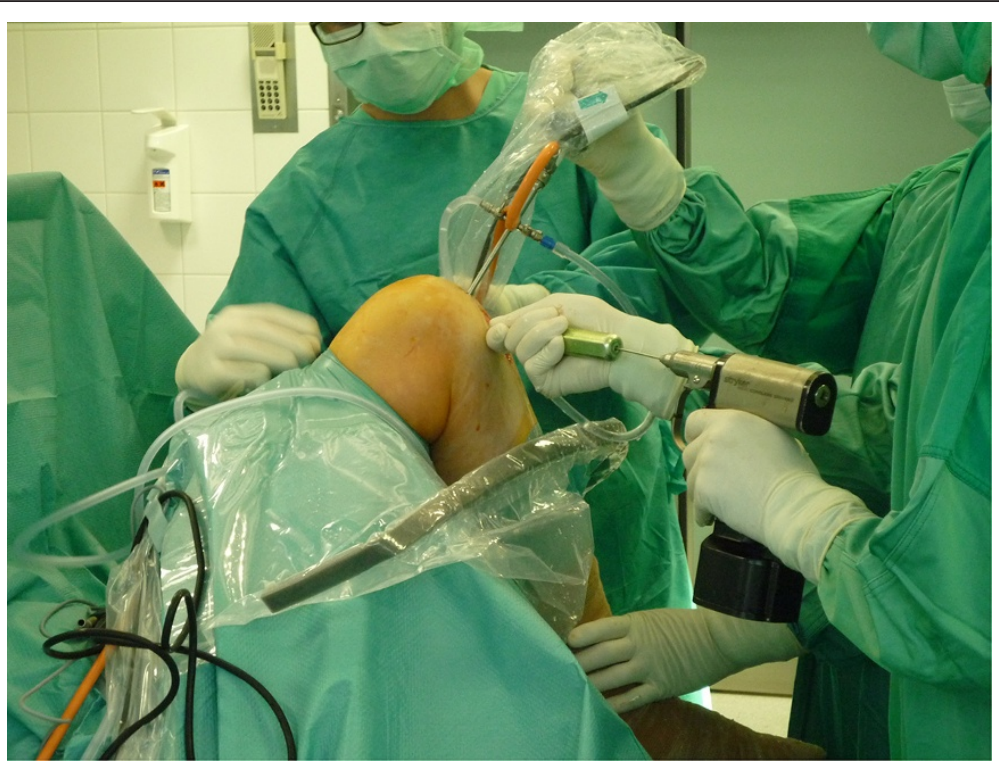

Figure 2 Drilling the femur tunnel through an anteromedial portal with the knee hyperflexed. 
knee [74]. Basdekis et al. has found that increasing the knee flexion when drilling from an anteromedial portal prevents femoral posterior wall blowout and gives longer femoral tunnel lengths [70].

Outside in femoral drilling was practised by surgeons for a long time. With surgeons revisiting independent drilling of femur and tibial tunnels in ACL reconstruction, many surgeons now use outside in drilling for femoral tunnels [75]. The benefits of outside-in drilling are: safety to the lateral knee structures, less risk of posterior wall blowout and longer femoral tunnel for graft fixation $[75,76]$.

\section{Graft Fixation}

The preference in The European centres we visited for femoral fixation of soft tissue hamstring grafts was suspensory cortical button fixation. Ahmad CS et al. found in a porcine biomechanical study that suspensory cortical femoral fixation had a higher ultimate failure load of $864 \mathrm{~N}$ and less graft slippage as compared to interference screw with a failure load of $539 \mathrm{~N}$ [77]. Various other authors have also shown that extracortical fixation has a mean load to failure of $700 \mathrm{~N}$ to $1150 \mathrm{~N}$ during biomechanical testing [78,79]. The failure load for the interference screw is close to $450 \mathrm{~N}$, which is what Noyes terms the physiological load that the knee has to withstand [80]. The drawbacks of suspensory cortical fixation are: a less stiff fixation construct and the bungee effect of suspensory button fixation on graft tunnel widening [81-83]. However, $\mathrm{Ma}$ et al. found that at 2 years, aperture fixation with bioabsorbable interference screw did not lead to significant differences in clinical outcomes or reduced tunnel widening when compared to the cortical suspensory fixation [84].

On the tibial side, we saw the preference for the use of bioabsorbable interference screws for tibial fixation. Some authors report that metal screws had a higher rate of graft laceration compared to bioabsorbable screws in hamstring
ACL reconstruction. [85,86] Moisala AS et el found that using certain bioabsorbable screw tibia fixation for ACL reconstruction led to $23 \%$ graft failure rates, compared to $6 \%$ with metal screws [87]. The meta-analysis that compared ACL reconstruction outcomes using bioabsobable and metallic screws, found no significant differences in functional outcomes or stability [88].

In two centres with hamstring ACL reconstruction, in addition to the use tibia bioabsorbable interference screws, we note the use of backup fixation with soft tissue staples. Walsh et al. in their porcine model biomechanical study found that soft tissue grafts fixed with a retroscrew backed-up with a suture button had higher ultimate failure loads and had stiffer constructs that grafts fixed with either the retroscrew or suture button alone [89]. Hill et al. in their randomised controlled study found that supplementary tibial staple fixation in female patients undergoing hamstring autograft ACL reconstruction with tibia interference screw fixation can reduce the knee laxity at 2-years awhen compared to tibia interference screw fixation alone [90]. These studies suggest benefit of the use of backup fixation in the tibia with selected patients.

\section{Tensiometer}

High graft tension induces poor vascularity, myxoid degeneration and deterioration in graft mechanical properties in a canine model [91,92]. Conversely, low graft tension produces knee laxity, changes in knee kinematics and progressive deterioration of tendon mechanical properties [93,94]. Chang et al. has shown that using a tensioner during graft fixation provided superior soft tissue graft tunnel fixation when compared to manual tensioning [95]. During our travelling fellowship, we note the widepread use of tensioners for graft fixation during ACL reconstruction (Figure 3). This is an important technical pearl as the use of a tensiometer, as compared

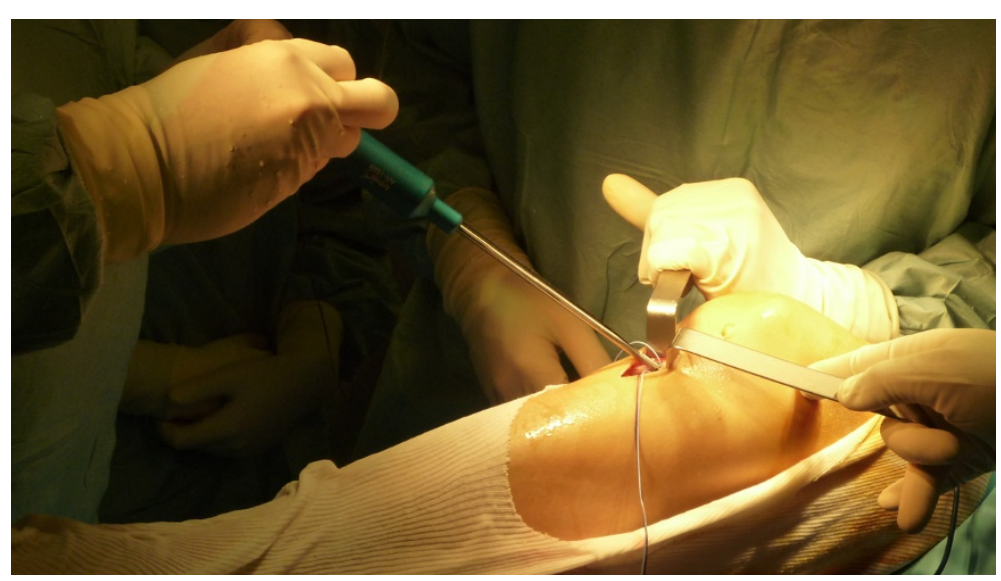

Figure 3 Using a tensiometer during final tensioning of the ACL with insertion of tibia interference screw. 
to manual tensioning is a critical step to ensure the longevity of a reconstructed ACL graft.

The optimal tension load and angle of flexion during tensioning has yet to agreed in the body of literature [96]. Numazaki et al. suggested that an initial tension of $20 \mathrm{~N}$ for patellar tendon grafts and going beyond $80 \mathrm{~N}$ for hamstring grafts is unnecessary [97]. Arnold MP et al. found that tensioning the graft at $10 \mathrm{~N}$ at $10 \mathrm{de}-$ gree of flexion allows the graft to be taut in all positions of flexion while avoiding excessive tension [98]. Tatsuo et al. found that the ACL graft fixed at 20 degrees of flexion is most optimal [99].

\section{Meniscus in $\mathrm{ACL}$}

The preference of the European surgeons we had visited,for meniscal injuries during ACL reconstruction was meniscus repair. Spand et al. has shown in their cadaveric biomechanical study that the meniscus is a secondary stabiliser of the ACL and a menisectomy produces an increased strain on the ACL [100]. Thus, preserving the meniscus in ACL surgery helps to protect graft from subsequent failure. The literature has shown that meniscus deficient knees are exposed to increased articular contact pressures and typically progress to joint degeneration [101-103].

Magnussen et al. in their metaananalysis on the effect of the meniscus on ACL outcomes at more than 2 years follow-up found that all patients who underwent partial menisectomy developed radiographic changes [104]. In their 24-year follow up of ACL reconstructed patients, Pernin J highlights the importance of meniscus preservation to prevent osteoarthritis. They found that only $38 \%$ patients with an intact medial meniscus had osteoarthritis, compared to $68 \%$ of patients with a previous menisectomy who developed osteoarthritis [105]. Brophy et al. found that contrary to belief, an isolated ACL does not significantly shorten the career nor reduce the playing time of an National Football League (NFL) athlete. However, they found that an isolated menisectomy significantly reduces career length and playing time of an NFL player [106].

\section{Chronic ACL}

Gerrit et al. have shown in their cadaveric knee study showed that an unstable ACL deficient knee with a varus thrust leads to an increased risk of ACL failure [107]. This emphasises the importance of simultaneous alignment correction in young patients with both chronic anterior knee instability and varus deformity - a combined high tibial osteotomy and ACL reconstruction is the recommended option [108,109]. Williams et al. showed that a simultaneous combined ACL reconstruction with a osteotomy to correct the varus alignment had superior short-term outcomes and a low complications rate [110]. Bonin et al. found that simultaneous combined ACL reconstruction and closed or open wedge HTO yielded satisfactory long-term outcomes [111].

During this fellowship, we had seen two cases of combined ACL reconstruction with high-tibia osteotomy. The key to the combined surgery is ensuring that the osteotomy plate does not block the position of the tibial tunnel during ACL reconstruction.

However, Latterman and co-authors have warned of the potential higher complication rates seen in such combined procedures. They had suggested that the procedure should be staged with the osteotomy performed followed by the ACL reconstruction in 9 to 12 months [112].

\section{Revision ACL}

In the MARS group descriptive epidemiology of ACL revisions, the combination $(37 \%)$ of a traumatic reinjury

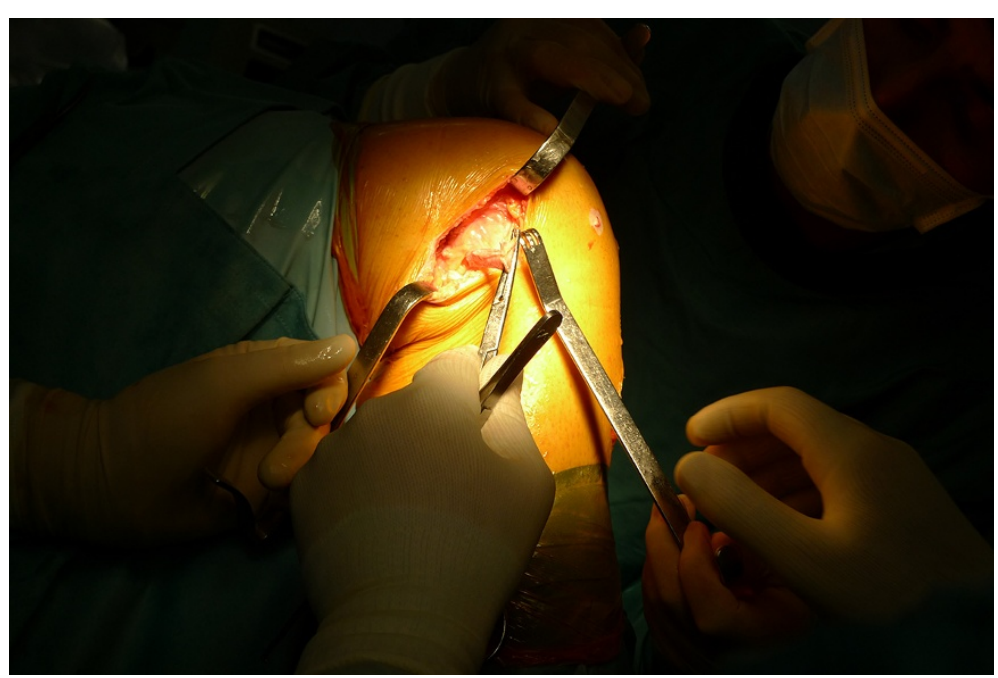

Figure 4 Extraarticular augmentation of iliotibial band during revision reconstruction of $A C L$. 
as well as technical reasons was the most common cause for the revision surgery [113]. Unlike the MARS group where more than $50 \%$ of revision ACL reconstructions were performed with allograft tissue, we saw the use of autograft tissue in revision ACL surgery- 2 BTB autograft and 1 hamstring autograft were used. We noted that in all cases that required revision, the femoral tunnel from the primary failed ACL reconstruction was placed too vertical and not in the described anatomical position. This meant that the revised femoral tunnel tunnel had to be drilled in a separate location and made the revision surgery less technically demanding.

In one centre, we also saw the use of an extraarticular augmentation of the iliotibial band (ITB) for revision anterior cruciate ligament.(Figure 4) This procedure start with the harvest of $1 \mathrm{~cm}$ wide and $20 \mathrm{~cm}$ long strip of iliotibial band, keeping the tibial attachment intact. The deep insertion of the ITB of the femur that lies posterior and proximal to the lateral epicondyle is identified. The ITB graft is fixed at this point in 30 degrees flexion and neutral internal rotation with a soft tissue washer screw. The graft is then looped back to the Gerdy tubercle and stitched down [114]. This technique is different from the extraarticular procedures in the 1980s where ITB grafts were routed beneath the fibular collateral ligament and sutured at the Gerdys tubercle $[115,116]$. These were non-anatomic placement of ITB grafts which do not restore the femoral tibial ITB attachments that resist internal rotation.

Two clinical studies by Noyes et al. and Ferretti et al. have shown that this extraarticular procedure added in ACL revision surgery significantly improves knee stability $[114,116]$. They believe that this extraarticular tenodesis procedure provides an additional restraint for tibial internal rotation and anterior translation.

\section{Conclusion}

ACL Reconstruction techniques has evolved with our improved understanding of anatomy, kinematics, physiometrics, and surgical outcomes. The travelling fellowship provides us with the opportunity to learn these techniques and best practices from the various European sports centres and see if we can apply it to improve our own patient outcomes.

\section{Competing interests}

The authors declare that they have no competing interests.

\section{Authors' contributions}

All authors (LYHD, RK, ZJZ, CKM) contributed, read and approved the final manuscript.

\section{Author details}

'Department of Orthopedic Surgery, Changi General Hospital, 2 Simei St 3 , Singapore 529889, Singapore. ${ }^{2}$ Department of Orthopedic Suregry, Kobe University Graduate School of Medicine, 7-5-2 Kusunoki-cho, Chuou-Ku, Kobe 650-0017, Japan. ${ }^{3}$ Department of Arthroscopy Surgery, Shanghai No 6
Peoples Hospital, Shanghai 200233, China. ${ }^{4}$ Department of Orthopedics \& Traumatology, The Chinese University of Hong Kong, Prince of Wales Hospital, Hong Kong SAR, PR China.

Received: 6 September 2011 Accepted: 3 July 2012

Published: 28 July 2012

\section{References}

1. Barker JU, Drakos MC, Maak TG, Warren RF, Williams RJ, Allen AA: Effect of graft selection on the incidence of postoperative infection in anterior cruciate ligament reconstruction. Am J Sports Med 2010, 38:281-286.

2. Campbell J: Treatment trends with $A C L, P C L, M C L$ and cartilage problems. Italy: ACL Study Group Meeting 2004 Sardinia; 2004.

3. Duquin TR, Wind WM, Fineberg MS, Smolinski RJ, Buyea CM: Current trends in anterior cruciate ligament reconstruction. J Knee Surgery 2009, 22:7-12.

4. Feller J, Cooper R, Webster K: Current Australian trends in rehabilitation following anterior cruciate ligament reconstruction. Knee 2001, 8:13-18.

5. Kapoor B, Clement DJ, Kirley A, Maffuli N: Currebt practice of management of anterior cruciate ligament injuries in the United Kingdom. Br J Sports Med 2004, 38:542-544.

6. Magnussen RA, Grana LP, Dunn WR, et al: Cross cultural comparison of patients undergoing $A C L$ reconstruction in the Unted States and Norway. Knee Surg Sports Traumatol Arthroc 2010, 18:98-105.

7. Mirza F, Mai DD, Kirley A, Fowler PJ, Amendola A: Management of Injuries to the Anterior Cruciate Ligament: Results of a Survey of Orthopedic Surgeons in Canada. Clin Journal of Sports Medicine 2000, 10:85-88.

8. Scheffler S, Schmidt T, Gangey I, Dustmann M, Unterhauser F, Weiler A: Fresh Frozen Free Tendon allograft versus autografts in Anterior Cruciate Ligament Reconstruction: Delayed Remodelling and Inferior Mechanical Function During Long-term Healing in Sheep. Arthroscopy 2008, 24:448-458.

9. Singhal MC, Gardiner JR, Johnson DL: Failure of Primary Anterior Cruciate Ligament Surgery Using Anterior Tibialis Allograft. Arthroscopy 2007, 23:469-475.

10. Nakata K, Shino K, Horibe S, Tanaka Y, Toritsuka Y, Nakamura N, Koyanagi M, Yoshikawa H: Arthroscopic Anterior Cruciate Ligament Reconstruction using Fresh Frozen Bone Plug-Free Allogenic Tendons: 10 year Followup. Arthroscopy 2008, 24:285-291.

11. Mascarenhas $R$, Tranovich M, Karpie JC, Irrgang JJ, Fu FH, Harner CD: Patellar Tendon Anterior Cruciate Ligament Reconstruction in the High Demand Patient: Evaluation of Autograft Versus Allograft Reconstruction. Arthroscopy 2010, 26:S58-S66.

12. Poehling GG, Curl WW, Lee CA, Ginn TA, Rushing JT, Naughton MJ, Holden MB, Martin DF, Smith BP: Analysis of Outcomes of Anterior Cruciate Ligament Repair with 5 year Follow-up: Allograft versus Autograft. Arthroscopy 2005, 21:774-785.

13. Rodeo SA, Arnoczky SD, Torzilli PA, Hidaka C, Warren RF: Tendon-healing in a bone tunnel: a biomechanical and histological study in the dog. J Bone Joint Surg Am 1993, 75-A:1795-1803.

14. Grana WA, Egle DM, Mahnken R, Goodhart CW: An analysis of autograft fixation after anterior cruciate ligament reconstruction in a rabbit model. Am J Sports Med 1994, 22:244-251.

15. Pinczewski LA, Deehan DJ, Salmon LKJ, Russel VJ, Clingeleffer AJ: A five year comparison of patellar tenon versus four strand hamstring autograft for arthroscopic reconstruction of the anterior cruciate ligament. Am J Sports Med 2002, 30:523-536.

16. Sajovic M, Vengust V, Komandina R, et al: A prospective, randomised comparison of semitendinosus and gracilis tendon versus patellar tendon autografts for anterior cruciate ligament reconstruction: five year follow-up. Am J Sports Med 2006, 34:1933-1940.

17. Kartus J, Marvin T, Karlsson J: Donor site morbidity and anterior knee pain problems after anterior cruciate ligament reconstruction using autografts. Arthroscopy 2001, 17:971-980.

18. Wagner M, Kaab MJ, Schallock J, Haas NP, Weiler A: Hamstring Tendon versus Patellar Tendon Anteriro Cruciate Ligament Reconstruction using Biodegradable Interference Fit Fixation. Am J of Sports Med 2005, 33:1327-1335.

19. Woo SL, Hollis JM, Adam DJ, Lyon RM, Takai S: Tensile properties of human femur-anterior cruciate ligament tibia complex. The effect of specimen age and orientation. Am J Sports Med 1991, 19:217-225. 
20. Hamner DL, Brown CH Jr, Steiner ME, Hecker AT, Hayes WC: Hamstring tendon grafts for reconstruction of anterior cruciate ligament: niomecahnical evaluation of the use of multiple strands and tensioning techniques. J Bone Joint Surg Am 1999, 81:549-557.

21. Cooper DE, Deng XH, Burstein AL, Warren RF: The strength of the central third patellar tendon graft. Am J Sports Med 1993, 21:818-823.

22. Fiedeler BM, Vangsness CT, Bin LU, Orlando C, Moore T: Gamma irridaiation: effect on biomechanical properties of human bone patellar tendon bone allografts. Am J Sports Med 1995, 23:63-66.

23. Haut-Donahue TL, Howell SM, Hull ML, Gregersen C: A biomechanical evaluation of anterior and posterior tibialis tendons as suitable single loop anterior cruciate ligament grafts. Arthroscopy 2002, 18:589-597.

24. Pearsall AW, Hollis JM, Russel GV, Scheer Z: A biomechanical evaluation comparison of three lower extremity tendons for ligamentous reconstruction about the knee. Arthroscopy 2003, 19:1091-1096.

25. Biau DJ, Katsahian S, Kartus J, Harilainen A, Feller JA, Saovic M, Ejerhed L, Zaffagini S, Ropke M, Nozard R: Patellar Tendon Versus Hamstring Tendon Autografts for Reconstructing the Anterior Cruciate Ligament: A Meta-Analysis Based on Individual Patient Data. Am J Sports Med 2009, 37:2470-2477

26. Harilainen A, Linko E, Sandelin J: Randomised prospective study of ACL reconstruction with interference screw fixation in patellar tendon autografts versus femoral metal plate suspension and tibial post fixation in hamstring tendon autografts: 5-year clinical and radiological followup results. Knee Surg Sports Traumatol Arthroc 2006, 14:517-528.

27. Ahlden M, Kartus J, Ejerhed L, Karlsson J, Sernert N: Knee laxity measurements after anterior cruciate ligament reconstruction, using either bone patellar tendon bone or hamstring autografts, with special emphasis on comparison over time. Knee Surg Sports Traumatol ArthrosC 2009, 17:1117-1124.

28. Holm I, Oiestad BE, Risberg MA, Aune AK: No difference in Knee Function or Prevalence of Osteoarthritis after reconstruction of the Anterior Cruciate Ligament with 4-strand Hamstring Autograft versus Patellar Tendon-Bone Autograft: A randomised study with 10-year follow-up. Am J Sports Med 2010, 38:448-454.

29. Samuelsson K, Andersson D, Karlson J: Treatment of Anterior Cruciate Ligament Injuries with Special Reference to Graft Type and Surgical Technique. Arthroscopy 2009, 10:1139-1174.

30. Muneta T, Sekiya I, Yagishita K, Ogiuchi T, Yamamoto H, Shinomiya K: Twobundle reconstruction of the anterior cruciate ligament using semitendinosus tendon with EndoButtons: Operative technique and preliminary results. Arthroscopy 1999, 15:618-624.

31. Yasuda $\mathrm{K}$, Kondo $\mathrm{E}$, Ichiyama $\mathrm{H}$, et al: Anatomical reconstruction of the anteromedial and posterolateral bundles of the anterior cruciate ligament using hamstring tendon grafts. Arthroscopy 2004, 20:1015-1025

32. Toritsuka Y, Amano H, Kuwano M, Iwai T, Mae T, Ohzono K, Shino K: Outcome double bundle $A C L$ reconstruction using hamstring tendons. Knee Surg Sports Traumatol Arthrosc. 2009, 17:456-463.

33. Tajima G, Iriuchishima T, Ingham SJ, Shen W, van Houten AH, Aerts MM Shimamura T, Smolinski P, Fu FH: Anatomic double-bundle anterior cruciate ligament reconstruction restores patellofemoral contact areas and pressures more closely than non-anatomic single bundle reconstruction. Arthroscopy 2010, 26:1302-1310.

34. Morimoto Y, Ferretti M, Ekdahl M, Smolinski P, Fu FH: Tibiofemoral joint contact area and pressure after single and double deundle anterior cruciate ligament reconstruction. Arthroscopy 2009, 25:62-69.

35. Yagi M, Kuroda R, Nagamune K, Yoshiya S, Kurosaka M: Double-bundle ACL reconstruction can improve rotational stability. Clin Orthop Relat Res 2007, 454:100-107.

36. Jong KS, Gadikota HR, Wu JL, Sutton K, Gill TJ, Li G: Comparison of single and double-bundle anterior cruciate ligament reconstructions in restoration of knee kinematics and anterior cruciate ligament forces. Am J Sports Med 2010, 38:1359-1367.

37. Zantop T, Diemann N, Schumacher T, Schanz S, Fu FH, Petersen W: Anatomical and nonanatomical double-bundle anterior cruciate ligament reconstruction: importance of femoral tunnel location on knee kinematics. Am J Sports Med 2008, 36:678-685.

38. Belisle AL, Bicos J, Geaney L, Andersen MH, Obopilwe E, Rincon L, Nyland J, Morgan C, Caborn DN, Arciero RA: Strain pattern comparison of double and single bundle anterior cruciate ligament reconstruction techniques with native anterior cruciate ligament. Arthroscopy 2007, 23:1210-1217.
39. Fu FH, Wei S, Starman JS, Okeke N, Irrgang JJ: Primary Anatomic doubleBundle Anterior Cruciate Ligament Reconstruction: A Preliminary 2-year prospective study. Am J Sports Med 2008, 36:1263.

40. Adachi N, Ochi M, Uchio Y, Iwasa J, Kuriwaka M, Ito Y: Reconstruction of the anterior cruciate ligament. Single versus double bundle multistranded hamstring tendons. J Bone Joint Surg Br 2004, 86:515-520.

41. Araki D, Kuroda $R$, Kubo $S$, et al: A prospective randomized study of anatomical single-bundle versus double-bundle anterior cruciate ligament reconstruction: Quatitative evaluation using an electromagnetic measurement system. Int Ortho 2011, 35:439-446.

42. Kanaya A, Ochi M, Deie M, Adachi N, Nishimori M, Nakamae A: Intraoperative evaluation of anteroposterior and rotational stabilities in anterior cruciate ligament reconstruction: lower femoral tunnel placed single-bundle versus double-bundle reconstruction. Knee Surg Sports Traumatol Arthroc 2009, 17:907-913.

43. Song EK, Oh LS, Gill TJ, Li G, Gadikota HR, Jong KS: Propsective Comparative Study of Anterior Cruciate Ligament Reconstruction using double-bundle and single bundle techniques. Am J Sports Med 2009, 37:1705-1711.

44. Meredick RB, Vance KJ, Appleby D, Lubowitz JH: Outcome of single-bundle versus double -bundle reconstruction of the anterior cruciate ligamentA Meta-Analysis. Am J Sports Med 2008, 36:1414-1421.

45. Fu FH, Karlsson J: A long road to be anatomic. Knee Surg Sports Traumatol Arthrosc 2010, 18:1151-1153.

46. Van Eck CF, Lesniak BP, Schreiber VM, Fu FH: Anatomic single-and double bundle anterior cruciate ligament reconstruction flowchart. Arthroscopy 2010, 26:258-268.

47. Van Eck CF, Schreiber WM, Liu TT, Fu FH: The anatomic approach to primary, revision and augmentation anterior cruciate ligament reconstruction. Knee Surg Sports Traumatol Arthrosc 2010, 18:1154-1163.

48. Hefzy MS, Grood ES, Noyes FR: Factors affecting the region of most isometric femoral attachements. Part II The anterior cruciate ligament. Am J Sports Med 1989, 17:208-216.

49. Sapega AA, Moyer RA, Schneck C, Komalahiranya N: Testing for isometry during reconstruction of anterior cruciate ligament. Anatomical and biomechanical considerations. J Bone Jont Surgery Am 1990, 72:259-267.

50. MusahI V, Plakseychuk A, VanScyoc A, Sasaki T, Debski RE, McMahon PJ, Fu $\mathrm{FH}$ : Varying Femoral Tunnels between theAnatomical Footprint and isometric positions: Effect on Kinematics of the Anterior Cruciate Ligament - Reconstructed Knee. Am J Sports Med 2005, 33:712-718.

51. Abebe ES, Utturkar GM, Taylor DC, Spritzer CE, Kim JP, Moorman CT III, Garrett WE, DeFrate LE: The effects of femoral graft placement on in vivo knee kinematics after anterior cruciate ligament reconstruction. J Biomech 2011, 44:924-929.

52. Zantop T, Petersen W, Fu FH: Anatomy of the Anterior Cruciate Ligament. Operative Techniques in Orthopedics 2005, 15:20-28.

53. Siebold R, Ellert T, Metz S, Metz J: Tibial Insertion of the Anteromedial and Posterolateral Bundles of the Anterior Cruciate Ligament: Morphometry, Arthroscopic Landmarks, and Orientation Model for Bone Tunnel Placement. Arthroscopy 2008, 24:154-161.

54. Siebold R, Ellert T, Metz S, Metz J: Femoral Insertions of the Anteromedial and Posterolateral bundles of the Anterior Cruciate Ligament; Morphometry and Arthroscopic Oreinettaion Models for double- bundle bone tunnel placement - a cadaver study. Arthroscopy 2008, 24:582-592.

55. Siebold R, Zantop T: Anatomic double-bundle ACL reconstruction: a call for indications. Knee Surg Sports Traumatol 2009, 17:211-212.

56. Shino K, Suzuki T, Iwahashi T, et al: The resident's ridge as an arthroscopic landmark for anatomical femoral tunnel drilling in $\mathrm{ACL}$ reconstruction. Knee Surg Sports Traumatol Arthrosc 2010, 18:1164-1168.

57. Bird JH, Carmont MR, Dhillon M, Smith N, Brown C, Thompson P, Spalding $\mathrm{T}$ : Validation of a new technique to determine midbundle femoral tunnel position in anterior cruciate ligament reconstruction using 3dimensional computed tomography analysis. Arthroscopy 2011, 27:1259-1267.

58. Girgis FG, Marhall $\lrcorner L$, Monajem A: The anterior cruciate ligaments of the knee joint. Anatomical, functional and experimental analysis. Clin Orthop 1975, 106:216-231.

59. Morgan CD, Kalman VR, Grawl DM: Definitive landmarks for reproducible tibial tunnel placement in anterior cruciatel ligament reconstruction. Arthroscopy 1995, 11:275-288. 
60. Jackson DW, Gasser Sl: Tibial tunnel placement in ACL reconstruction. Arthroscopy 1994, 10:124-131.

61. Kongcharoensombat W, Ochi M, Abouheif M, Adachi N, Ohkawa S, et al: Thetransverse ligament as a landmark for tibial sagittal insertions of the anterior cruciate ligament: A cadaveric study. Arthroscopy 2011, 27:1395-1399.

62. Adachi $N$, Ochi M, Uchio Y, Sumen Y: Anterior cruciate ligament augumentation under arthroscopy; A minimum 2-year follow-up in 40 patients. Arch Orthop Traum Surg 2000, 120:128-133.

63. Ochi M, Adachi N, Deie M, Kanaya A: Anterior cruciate ligament augumentation procedure with 1-incision technique;anteromedial bundle or posterolateral bundle reconstruction. Arthroscopy 2006, 463:e1-e5.

64. Asahina S, Muneta T, Ezura Y: Notchplasty in anterior cruciate ligament reconstruction: An experimental animal study. Arthroscopy 2000, 16:165-172.

65. Van Eck CF, Schreiber VM, Mejia HA, Samuelsson K, van Dijk CN, Karlsson J, Fu FH: Anatomic Anterior Cruciate Ligament Reconstruction: A systematic review of surgical techniques and reporting of surgical data. Arthroscopy 2010, 26:S2-S12.

66. La Prade RF, Terry GC, Montgomery RD, Curd D, Simmons DJ: The Effects of Aggressive Notchplasty on the Normal Knee in Dogs. Am J Sports Med 1998, 26:193-200

67. Markolf KL, Hame SL, Hunter DM, Oakes D, Gause P: Biomechanical effects of femoral notchplasty in anterior cruciaye ligament reconstruction. $\mathrm{Am} J$ Sports Med 2002, 30:83-89.

68. Bedi A, Musahl V, Steuber V, Kendoff D, Choi D, Allen AA, Pearle AD, Altchek DW: Transtibial versus Anteromedial Portal reaming in Anterior Cruciate Ligament Reconstruction: An anatomic and Biomechanical Evaluation of Surgical Technique. Arthroscopy 2011, 27:380-390.

69. Alentorn-Geli E, Samitier G, Alvarez P, Steinbacher G, Cugat R: Anteromedial portal versus transtibial drilling techniques in $\mathrm{ACL}$ reconstruction: a blinded cross-sectional study at two-five year follow-up. Int Orthop 2010, 34:747-754.

70. Basdekis G, Abisafi C, Christel P: Influence of Knee flexion angle on femoral tunnel characteristics when drilled through the anteromedial portal during Anterior Cruciate Ligament Reconstruction. Arthroscopy 2008, 24:459-464.

71. Farrow LD, Parker RD: The relationship of lateral anatomic structures to exiting guide pins during femoral tunnel preparation utilizing an accessory medial portal. Knee Surg Sports Traumatol Arthrosc 2010, 18:747753.

72. Hall MP, Ryzewicz M, Walsh PJ, Sherman $\mathrm{OH}$ : Risk of iatrogenic injury to the Peronel Nerve during Posterolateral Femoral tunnel Placement in Double bundle Anterior Cruciate Ligament reconstruction. Am J Sports Med 2009, 37:109-113.

73. Nakamura M, Deie M, Shibuya H, Nakamae A, Adachi N, Aoyama H, Ochi M: Potential risks of femoral tunnel drilling through the far anteromedial portal: a cadaveric study. Arthroscopy 2009, 25:481-487.

74. Van Eck CF, Morse KR, Fu FH: The anteromedial portal for anterior cruciate ligament reconstruction. Arthroscopy 2009, 25:1062-1064.

75. Lubowitz J, Konicek J: Anterior Cruciate Ligament Femoral Tunnel Length: Cadaveric Analysis Comparing Anteromedial Portal Versus Outside- In Technique. Arthroscopy 2010, 26:1357-1362.

76. Lubowitz J: Anteromedial portal technique for Anterior Cruciate Ligament Femoral Socket: Pitfalls and Solutions. Arthroscopy 2009, 25:95-101.

77. Ahmad CS, Gardner TR, Groh M, Arnouk J, Levine WN: Mechanical Properties of Soft Tissue femoral Fixation devices for Anterior Cruciate Ligament Reconstruction. Am J Sports Med 2004, 32:635-640.

78. Milano G, Mulas PD, Ziranu F, Piras S, Manuta A, Fabbriciani C: Comparison between different femoral fixation devices for $A C L$ Reconstruction with doubled Hamstring Tendon Graft: A Biomechanical Analysis. Arthroscopy 2006, 22:660-668.

79. Miller CD, Gerdeman AC, Bennett CG, Hart JM, Miller MD: A Biomechanical Comparison of the Endobutton $\mathrm{CL}$ using transtibial and endobutton direct using anteromedial arthroscopic drilling. Arthroscopy 2010, 26:1311-1317.

80. Noyes FR, Butler DL, Grood ES, Zernicke RF, Hefzy MS: Biomechanical analysis of human ligament grafts used in knee ligament repairs and reconstructions. J Bone Joint Surg Am 1984, 66:344-352.
81. Fauno $P$, Kaalund $S$ : Tunnel widening after hamstring anterior cruciate ligament reconstruction is influenced by type of graft fixation used: a prospective randomized study. Arthroscopy 2005, 21:1337-1341.

82. Hoher J, Moller HD, Fu FH: Bone tunnel enlargement after anterior cruciate ligament reconstruction: fact or fiction? Knee Surg. Sports Traumatol Arthrosc 1998, 6:231-240.

83. Steiner ME, Hecker AT, Brown CH, Hayes WC: Anterior Cruciate ligament graft fixation. Comparison of hamsring and patellar tendon grafts. Am J Sports Med 1994, 22:240-246.

84. $\mathrm{Ma} \mathrm{CB}$, Francis $\mathrm{K}$, Towers J, Irrgang J, Fu FH, Harner CH: Hamstring Anterior Cruciate Ligament Reconstruction: A comparison of Bioabsorbable Interference Screw and Endobutton-Post Fixation. Arthroscopy 2004, 20:122-128.

85. Brand J, Nyland J, Caborn D, et al: Soft tissue interference fixation: bioabsorbable screw versus metal screw. Arthroscopy 2005, 21:911-916.

86. Zantop T, Weiman A, Schmidtko R, Herbort M, Raschke MJ, Petersen W: Graft Laceration and Pullout Strength of Soft-Tissue Anterior Cruciate Ligament Reconstruction: In Vitro Study Comparing Titanium, Poly-D, L-Lactide and Poly-D, L-Lactide -Tricalcium Phosphate Screws. Arthroscopy 2006, 22:1204-1210.

87. Moisala AS, Jarvela T, Paakkala A, Paakkala T, Kannus P, Jarvinen M: Comparison of the bioabsorbable and metal screw fixation after $\mathrm{ACL}$ reconstruction with hamstring autograft in MRI and clinical outcome: a prospective randomised study. Knee Surg Sports Traumatol Arthrosc 2008, 16:1080-1086.

88. Shen C, Jiang SD, Jiang LS, Dai LY: Bioabsorbable versus Metallic Intefernce Screw Fixation In Anterior Cruciate Ligament Reconstruction: A Meta-Analysis of Randomised Controlled Trials. Arthroscopy 2010, 26:705-713.

89. Walsh MP, Wijdicks CA, Parker JB, Hapa O, LaPrade RF: A comparison between retrointerference screw, suture button and combined fixation on tibial side of an all-inside anterior cruciate ligament reconstruction. A Biomechanical study in a porcine model. Am J Sports Med 2009, 37 (1):160-167.

90. Hill PF, Russell VJ, Salmon L: Pinczewski. The influence of supplementary tibial fixation on laxity measurements after anterior cruciate ligament reconstruction with hamstring tendons in female patients. Am J Sports Med 2005, 33:94-101.

91. Yoshiya S, Andrish JT, Manley MT, et al: Graft tension in anterior cruciate ligament reconstruction. An in vivo study in dogs. Am J Sports Med 1987, 15:464-470.

92. Kasturagi R, Yasuda K, Tsujini J, et al: The effect of nonphsiologic high initial tension on mechanical properties of in-situ frozen anterior cruciate ligament in a canine model. Am J Sports Med 2000, 28:47-56.

93. Burks RT, Leland R: Determination of graft tension before fixation in anterior cruciate ligament reconstruction. Arthroscopy 1988, 4:260-266.

94. Tohyama H, Yasuda K: Significance of graft tension in anterior cruciate ligament reconstruction: Basic Background and clinical outcome. Knee Surg Sports Traumatol Arthrosc 1998, 6:S30-S37.

95. Chang HC, Nyland J, Nawab A, Burden R, Caborn NM: Biomechanical Comparison of Bioabsorbable RetroScrew System, BioScrew XtraLok with Stress Equalisation tensioner, and $35 \mathrm{~mm}$ Delta Screws for Tibialis Anteriro Graft-Tibial Tunnel Fixation in Porcine Tibia. Am J Sports Med 2005, 33:1057-1064.

96. Arneja S, McConkjey MO, Mulpuri K, Chin P, Gilbart MK, Regan WD, Leith J: Graft Tensioing in Anterior Cruciate Ligament Reconstruction: A Systematic Review of Randomized Controlled Trials. Arthroscopy 2009, 25:200-207.

97. Numazaki H, Tohyama H, Nakano H, Kikuchi S, Yasuda K: The Effect of Initial Graft tension in Anteriro Cruciate Ligament Reconstruction on Mechanical Behavious of Femur-Graft-Tibia Complex During Cyclic Loading. Am J Sports Med 2002, 30:800-805.

98. Arnold MP, Verdonschot N, Kampen AV: The Normal ACL as a model for tensioning strategies in ACL grafts. Am J Sports Med 2005, 33:277-283.

99. Tatsuo M, Shino K, Nakata K, Toritsuka Y, Otsubo H, Fujie H: Optimization of Graft Fixation at Time of Anteriro Cruciate Ligament reconstruction. Part II: Effect of Knee Flexion Angle. Am J Sports Med 2008, 36:1094-1100.

100. Spang JT, Dang ABC, Mazzocca A, Rincon L, Obopilwe E, Beynnon B, Arciero RA: The effect on Medial Menisectomy and Meniscus Allograft Transplanation on Knee and Anterior Cruciate Ligament Biomechanics. Arthroscopy 2010, 26:192-201. 
101. Fairbank TJ: Knee joint changes after Menisectomy. J Bone Joint Surgery Br 1948, 30:664-670.

102. Baratz ME, Fu FH, Mengato R: Meniscal tears: the effect of menisectomy and of repair on intraarticular contact areas and stress in the human knee. A preliminary report. Am J Sports Med 1986, 14:270-275.

103. Kurosawa $H$, Fukubayashi T, Nakajima H: Load-bearing mode of the knee joint. Physical behaviour of the knee joint with or without menisci. Clin Ortho Relat Res 1980, 149:283-290.

104. Magnussen RA, Mansour AA, Carey JL, Spindler KP: Meniscus status at Anterior Cruciate Ligament reconstruction associated with radiographic signs of osteoarthritis at 5 to 10 year follow-up. A systematic review. $J$ Knee Surg 2009, 22:347-357.

105. Pernin J, Verdonk P, Si Selmi TA, Massin P, Neyret P: Long-term follow-up of 24.5 years after intraarticular Anterior Cruciate Ligament Reconstruction with Lateral Extra-Articular Augmentation. Am J Sports Med 2010, 38:1094-1102.

106. Brophy RH, Gill CS, Lyman S, Barnes RP, Rodeo SA, Warren RF: Effect of Anterior Cruciate Ligament Reconstruction and Menisectomy on Length of Carrer in National Football League Atheletes: A Case Control Study. An J Sports Med 2009, 37:2102-2107.

107. Gerrit JVP, Arnold MP, Verdonschot N, van Kampen A: Varus alignment leads to increased forces in the anterior cruciate ligament. Am J Sports Med 2009, 37:481-487.

108. Noyes FR, Barber-Westin SD, Hewett TE: High tibial osetotomy and ligament reconstruction for varus angulated anterior cruciate ligament deficient knees. Am J Sports Med 2000, 28:282-296.

109. Williams RJ III, Kelly BT, Wickiewicz TL, Atchek DW, Warren RF: The shortterm outcome of surgical treatment for painful arthritis in association with chronic ACL deficiency. J Knee Surg 2003, 16:9-16.

110. Williams RJ 3rd, Wickeiwicz TL, Warren RF: Management of unicompartmental arthritis in the anterior cruciate ligament deficient knee. Am J Sports Med 2000, 28:749-760.

111. Bonin N, Ait Si Selmi T, Donell ST, Dejour H, Neyret P: Anterior cruciate reconstruction combined with valgus upper tibial osteotomy: 12 years follow-up. Knee 2004, 11:431-437.

112. Latterman C, Jacob RP: High Tibial Osteotomy alone or combined with ligament reconstruction in anterior cruciate ligament deficient knees. Knee Surg Sports Traumatol Arthrosc 1996, 4:32-38.

113. Wright RW, et al: The Mars Group. Descriptive Epidemiology of the Multicenter ACL Revision Study (MARS) Cohort. American. J Sports Med 2010, 38:1979-1986.

114. Noyes FR, Barber SD: The effect of an extra-articular procedure on allograft reconstructions for chronic ruptures of the anterior cruciate ligament. J Bone Joint Surg Am 1991, 73:882-892.

115. Marcacci M, Zaffagnini S, Giodarno G, lacono F, Presti LM: Anterior Cruciate Ligament Reconstruction Associated with Extra-articular Tenodesis: A Prospective Clinical and Radiographic Evaluation with 10-13 year followup. Am J Sports Med 2009, 37:707-714.

116. Ferretti A, Conteduca F, Monaco E, De Carli A, D'Arrigo C: Revision anterior cruciate ligament reconstruction with doubled semitendinosus and gracilis tendons and lateral extraarticular reconstruction. J Bone joint Sur Am 2006, 88:2373-2379.

doi:10.1186/1758-2555-4-27

Cite this article as: Lee et al:: A tale of 10 European centres - 2010

APOSSM travelling fellowship review in ACL surgery. Sports Medicine, Arthroscopy, Rehabilitation, Therapy \& Technology 2012 4:27.

\section{Submit your next manuscript to BioMed Central and take full advantage of:}

- Convenient online submission

- Thorough peer review

- No space constraints or color figure charges

- Immediate publication on acceptance

- Inclusion in PubMed, CAS, Scopus and Google Scholar

- Research which is freely available for redistribution

Submit your manuscript at www.biomedcentral.com/submit
C Biomed Central 